\title{
LA CONSTITUCIÓN FEDERAL, LAS LEYES SECUNDARIAS Y EL DERECHO INTERNACIONAL; REGLAS QUE RIGEN LOS CONTRATOS MERCANTILES INTERNACIONALES
}

\section{ÓSCAR VÁSQUEZ DEL MERCADO CORDERO'}

\begin{abstract}
RESUMEN: El presente trabajo de investigación se centra en el tema relacionado con el desafío y los compromisos que impone el fenómeno de la globalización económica en el desarrollo de la contratación mercantil internacional, toda vez que dicho fenómeno involucra aspectos financieros, tecnológicos, jurídicos, políticos y sociales, que desencadenan el desarrollo del comercio y la contratación mercantil, es por ello que este ensayo se refiere particularmente a lo relativo a las reglas que rigen los contratos mercantiles internacionales, considerando en principio lo que respecto al comercio establecen, la Constitución Política de los Estados Unidos Mexicanos y las leyes secundarias, para abordar de lleno la problemática de la falta de uniformidad de dichas reglas en el derecho internacional y la repercusión de éstas.

PAlABRAs ClAve: Constitución, contratos internacionales, leyes, derecho internacional, derecho internacional convencional, derecho internacional consuetudinario, derecho mercantil, derechos humanos, globalización, comercio, sistema jurídico, monopolio, prácticas monopólicas, acto de comercio y lex mercatoria.
\end{abstract}

ABSTRACT: This research work focuses on the topic related to the challenge and the commitments imposed by the phenomenon of economic globalization on the development of the international commercial contracts, as this phenomenon involves financial, technological, legal, political and social aspects that trigger the development of trade and commercial contracts, therefore, that this trial concerns particularly with regard to the rules governing international commercial contracts whereas in principle that

1 Licenciado y Doctor en Derecho (con mención honorífica) por la Universidad Nacional Autónoma de México. Investigador Nacional Nivel I, en el Sistema Nacional de Investigadores de CONACYT. Catedrático de tiempo completo en la Facultad de Derecho de la UNAM. Miembro de número en la Academia Mexicana de Legislación y Jurisprudencia y en el Ilustre y Nacional Colegio de Abogados de México. Correo electrónico <oscarvmc@gmail.com>. 
with respect to trade established, the political Constitution of the Mexican United States and secondary laws, to address squarely the problem of the lack of uniformity of rules in international law and the impact of these.

KEY WORDS: Constitution, international agreements, laws, international law, international treaty law, customary international law, human rights, globalization, trade, legal system, monopoly, monopolistic practices, act of trade and lex mercatoria.

Sumario: I. Introducción; II. Constitución Política de los Estados Unidos Mexicanos y leyes secundarias; III. Derecho internacional.

\section{INTRODUCCIÓN}

T T na rama del derecho a la que por años he dedicado mi vida profesional, docente y de investigación, es el derecho mercantil; en esta ocasión centraré mi atención en el tema relacionado con el desafío y los compromisos que impone el fenómeno de la globalización económica en el desarrollo de la contratación mercantil internacional, particularmente en lo relativo a las reglas que rigen los contratos mercantiles internacionales, considerando en principio lo que respecto al comercio establecen, la Constitución Política de los Estados Unidos Mexicanos y las leyes secundarias, para abordar de lleno la problemática de la falta de uniformidad de dichas reglas en el derecho internacional.

Es conveniente señalar que a la globalización generalmente se le define en función de la economía de los países, sin embargo, es claro que involucra además aspectos financieros, tecnológicos, jurídicos, políticos, sociales y muchos más, que interrelacionan a los países y a las personas, por lo tanto, de alguna manera los hacen interdependientes, de tal manera el término globalización es multívoco.

Se destaca que la tecnología como fuerza motriz que mueve la maquinaria de la globalización, impulsa la producción de bienes y servicios, en los cambios relacionados con el comercio y en los patrones actuales de inversión mundial. 
Refiriéndome a cuestiones económicas, se destaca que la tecnología propicia cambios en el comercio y patrones actuales de inversión mundial, al tiempo que se asocia en particular con la ciencia de la informática y de las telecomunicaciones, ya que multiplica los flujos de información a través del planeta, haciendo del conocimiento un factor de la producción más importante y rentable que el trabajo, el capital o las materias primas. ${ }^{2} \mathrm{El}$ uso de internet se ha generalizado a nivel mundial, las redes sociales son actualmente un medio de comunicación automática y masiva que asombra a cualquiera, en la contratación mercantil nacional e internacional, internet proporciona una gran gama de posibilidades antes insospechadas, para el intercambio de bienes y servicios en la comunidad internacional y apunto como ejemplo el comercio electrónico que se desarrolla a pasos agigantados entre lugares, personas y países a distancias remotas.

Así, resulta claro que la transformación de las economías de los países, consecuente y obligada por este fenómeno de la globalización, tiene que ver con el desarrollo del comercio y la contratación mercantil internacional y estos a su vez, con las reglas que los rigen, basadas en usos y costumbres y una gran variedad de normas nacionales e internacionales, que por falta de uniformidad, en caso de interpretación, cumplimiento o controversia entre las partes, generan conflictos de leyes y de jurisdicciones.

Por ello, acotando la globalización a lo económico, entre otras consecuencias, no puede negarse que abrió las fronteras de los países en el mundo, a la comercialización de una gran variedad de productos y servicios y que se han creado zonas de libre comercio. Las relaciones comerciales entre habitantes de distintos países, al igual que entre los Estados, actualmente son cada vez más frecuentes y complejas, muestra de ello son los convenios, acuerdos comerciales, tratados internacionales y otros instrumentos jurídicos en materia comercial, en los que asumen una serie de obligaciones de carácter

2 Rey Acosta Barradas, Los Desafios de la Globalización en México (Una Perspectiva Regional), México, UV, 2005, p. 41. 
mercantil, como es el caso de México, que ha celebrado convenios comerciales con la República Árabe Unida, Corea, China, Rumania, Hungría, antigua Checoslovaquia, Jamaica, Polonia, Bulgaria, Cuba, Japón, entre otros, así como el Tratado de Libre Comercio de América del Norte, que nuestro país celebró con Estados Unidos y Canadá.

Por lo antes expuesto, el análisis de este tema es de particular importancia, pues sirve como instrumento para detectar la problemática que vive actualmente el comercio internacional, además nos es útil para tratar de entender qué lugar ocupa nuestro país como sistema jurídico soberano, a partir de la premisa de que en el concierto internacional compartimos, vicisitudes, confusiones y yerros con otras naciones, que al igual que la nuestra tratan de salir de su atraso económico y aspiran encontrar en las instituciones jurídicas un mecanismo idóneo para su inserción igualitaria en el contexto económico mundial, particularmente en la contratación mercantil cada día más agresivo, ágil y complejo, que a manera de grandes desafíos, nos obligan a los juristas a asumir compromisos para el planteamiento de propuestas de reformas que conlleven a la unificación de las reglas que rigen los contratos mercantiles internacionales.

Es por lo anterior que a partir del análisis de las normas que establecen la Constitución Política de los Estados Unidos Mexicanos y las leyes secundarias, así como el derecho internacional en materia de comercio y particularmente en cuanto a los contratos mercantiles, me referiré especialmente a las reglas que los rigen en el ámbito internacional, mismas que sin duda han roto esquemas tradicionales de contratación.

\section{il. Constitución Política de los Estados Unidos MEXICANOS Y LEYES SECUNDARIAS}

En el sistema jurídico de nuestro país, los artículos $1^{\circ}$ y $5^{\circ}$ de la Constitución Política de los Estados Unidos Mexicanos reconocen 
los derechos humanos de igualdad y de libertad de todas las personas para ejercer el comercio, ya que en lo conducente disponen:

Artículo $1^{\circ}$ - En los Estados Unidos Mexicanos todas las personas gozarán de los derechos humanos reconocidos en esta Constitución y en los tratados internacionales de los que el Estado Mexicano sea parte, así como de las garantías para su protección, cuyo ejercicio no podrá restringirse ni suspenderse, salvo en los casos y bajo las condiciones que esta Constitución establece.

Artículo $5^{\circ}$ - A ninguna persona podrá impedirse que se dedique a la profesión, industria, comercio o trabajo que le acomode, siendo lícitos. El ejercicio de esta libertad sólo podrá vedarse por determinación judicial, cuando se ataquen los derechos de tercero, o por resolución gubernativa, dictada en los términos que marque la ley, cuando se ofendan los derechos de la sociedad.

Lo anterior de tal manera que, por un lado, todas las personas gozamos de la garantía de igualdad para el ejercicio de los derechos humanos que la Constitución Federal reconoce y que reconocen los tratados internacionales de los que México sea parte, por lo tanto podemos ejercer el comercio, siempre que sea lícito, es decir, que no contravenga lo que la propia Constitución y las leyes secundarias disponen, así como tampoco debe contravenir los tratados internacionales en la materia, sin embargo, como lo establece el artículo $5^{\circ}$ antes transcrito, el ejercicio de la libertad de comercio puede vedarse por resolución judicial cuando se ataquen derechos de tercero o por resolución gubernativa en términos de ley cuando se ofendan los derechos de la sociedad.

Pero el ejercicio de la libertad de comercio también queda protegido por la propia Constitución Federal, ya que en su artículo 28 prohíbe los monopolios y los estancos y garantiza la libre concurrencia en el mercado, a más de que, dicho sea de paso, prohíbe la exención de impuestos, lo que de suyo se justifica porque éstos son generales, es decir, todos los gobernados nos encontramos obligados a pagar impuestos para contribuir al gasto público, aunque debo 
señalar también que de la manera proporcional y equitativa que establezcan las leyes, por así disponerlo el artículo 31, fracción IV de la propia Carta Magna.

Además de lo antes mencionado, el artículo 28 de la Constitución Federal, contiene garantías de libertad, propiedad, legalidad y seguridad jurídica, para ejercer el derecho humano del comercio, al tiempo que establece diversas prohibiciones, excepciones, ventajas y sanciones, que expongo enseguida:

\section{PROHIBICIONES}

El artículo 28 de la Constitución Federal prohíbe los monopolios, los estancos y la competencia desleal y garantiza la libre concurrencia en el mercado, pues establece que en nuestro país está prohibida toda concentración o acaparamiento en una o pocas manos de artículos de consumo necesario y que tenga por objeto obtener el alza de los precios, al igual que todo acuerdo, procedimiento o combinación de los productores, industriales, comerciantes o prestadores de servicios, que de cualquier manera hagan, para evitar la libre concurrencia o la competencia entre sí y obligar a los consumidores a pagar precios exagerados y, en general, todo lo que constituya una ventaja exclusiva indebida a favor de una o varias personas determinadas y con perjuicio del público en general o de alguna clase social.

Por lo tanto, si bien la Constitución Federal garantiza el derecho humano para ejercer el comercio y la libre concurrencia en el mercado, por otro lado, en sus leyes secundarias reglamentarias también garantiza derechos de productores, distribuidores y comerciantes de bienes y servicios, así como de consumidores.

En efecto, una de las leyes reglamentarias del artículo 28 de la Constitución Federal, la Ley Federal de Competencia Económica, ${ }^{3}$ en su artículo 23 establece que la Comisión Federal de Competen-

\footnotetext{
3 Publicada en el Diario Oficial de la Federación del 24 de diciembre de 1992.
} 
cia, como órgano administrativo desconcentrado de la Secretaría de Economía, cuenta con autonomía técnica y operativa, para prevenir, investigar y combatir los monopolios, las prácticas monopólicas y las concentraciones, en los términos de la propia ley y gozará de autonomía para dictar sus resoluciones, mientras que el artículo 24 concede a la Comisión múltiples atribuciones en la materia, de las que me permito destacar:

- Investigar la existencia de monopolios, prácticas monopólicas, estancos o concentraciones contrarias a esta Ley para lo cual podrá requerir a los particulares y agentes económicos la información o documentos que estime relevantes y pertinentes;

- Establecer mecanismos de coordinación con las autoridades federales, estatales y municipales para el combate y prevención de monopolios, concentraciones y prácticas prohibidas por esta Ley;

- Resolver los casos de su competencia, sancionar administrativamente la violación de esta Ley y, en su caso, denunciar ante el Ministerio Público las probables conductas delictivas en materia de competencia y libre concurrencia de que tenga conocimiento;

- Resolver sobre condiciones de competencia, competencia efectiva, existencia de poder sustancial en el mercado relevante $\mathrm{u}$ otras cuestiones relativas al proceso de competencia o libre concurrencia a que hacen referencia ésta u otras leyes, reglamentos o disposiciones administrativas;

- Investigar la existencia de monopolios, prácticas monopólicas, estancos o concentraciones contrarias a esta Ley, incluyendo aquéllos que pudieren realizar los agentes económicos a que se refieren los artículos $4^{\circ}, 5^{\circ}$ y $6^{\circ}$ de este mismo ordenamiento, respecto de los actos que no estén expresamente comprendidos dentro de la protección que señala el artículo 28 constitucional, para lo cual podrá requerir a los particulares y agentes económicos la información o documentos que estime relevantes y pertinentes; 
En esta materia, otra ley reglamentaria del artículo 28 de nuestra Carta Magna, la Ley Federal de Protección al Consumidor, ${ }^{4}$ regula las relaciones entre los prestadores de bienes y servicios y los consumidores; por virtud de su artículo $1^{\circ}$, esta ley es de orden público e interés social y de observancia en toda la república, sus disposiciones son irrenunciables y contra su observancia no podrán alegarse costumbres, usos, prácticas, convenios estipulaciones en contrario, mientras que su objeto es el de promover y proteger los derechos y cultura del consumidor y procurará la equidad, certeza y seguridad jurídica en las relaciones entre proveedores y consumidores.

El mismo artículo precisa los siguientes principios básicos en las relaciones de consumo.

I. La protección de la vida, salud y seguridad del consumidor contra los riesgos provocados por productos, prácticas en el abastecimiento de productos y servicios considerados peligrosos o nocivos;

II. La educación y divulgación sobre el consumo adecuado de los productos y servicios, que garanticen la libertad para escoger y la equidad en las contrataciones;

III. La información adecuada y clara sobre los diferentes productos y servicios, con especificación correcta de cantidad, características, composición, calidad y precio, así como sobre los riesgos que representen;

IV. La efectiva prevención y reparación de daños patrimoniales y morales, individuales o colectivos;

V. El acceso a los órganos administrativos con vistas a la prevención de daños patrimoniales y morales, individuales o colectivos, garantizando la protección jurídica, económica, administrativa y técnica a los consumidores;

VI. El otorgamiento de información y de facilidades a los consumidores para la defensa de sus derechos;

4 Publicada en el Diario Oficial de la Federación del 24 de diciembre de 1992. 
VII. La protección contra la publicidad engañosa y abusiva, métodos comerciales coercitivos y desleales, así como contra prácticas y cláusulas abusivas o impuestas en el abastecimiento de productos y servicios.

VIII. La real y efectiva protección al consumidor en las transacciones efectuadas a través del uso de medios convencionales, electrónicos, ópticos o de cualquier otra tecnología y la adecuada utilización de los datos aportados;

IX. El respeto a los derechos y obligaciones derivados de las relaciones de consumo y las medidas que garanticen su efectividad y cumplimiento; y

X. La protección de los derechos de la infancia, adultos mayores, personas con discapacidad e indígenas.

Asimismo, el último párrafo del artículo $1^{\circ}$ de la misma ley protectora del consumidor, establece que los derechos que la misma consagra no excluyen otros derivados de tratados o convenciones internacionales de los que nuestro país sea parte y de los que deriven de los principios generales del derecho, la analogía, las costumbres y la equidad.

Inclusive, para uniformar las cláusulas de los contratos de adhesión que se utilizan para la adquisición de bienes y servicios, el artículo 85 de esta ley señala que se entiende por contrato de adhesión, el documento elaborado unilateralmente por el proveedor para establecer en formatos uniformes los términos y condiciones aplicables a la adquisición de un producto o la prestación de un servicio, aun cuando dicho documento no contenga todas las cláusulas ordinarias de un contrato. También señala que todo contrato de adhesión celebrado en territorio nacional, para su validez, deberá estar escrito en idioma español y sus caracteres tendrán que ser legibles a simple vista y en un tamaño y tipo de letra uniforme. Además, no podrá implicar prestaciones desproporcionadas a cargo de los consumidores, obligaciones inequitativas o abusivas, o cualquier otra cláusula o texto que viole las disposiciones de esta ley. 


\section{ExCEPCIONES}

El artículo 28 de la Constitución Federal señala que no constituirán monopolio, las funciones que el Estado ejerza de manera exclusiva en las áreas estratégicas, a saber: las que a través del banco central realice respecto de la acuñación de moneda y emisión de billetes; correos; telégrafos; radiotelegrafía; petróleo y demás hidrocarburos; petroquímica básica; minerales radioactivos; generación de energía nuclear; electricidad y; actividades que expresamente señalen las leyes que expida el Congreso de la Unión. Así como tampoco constituyen monopolio las actividades que se ejerzan sobre las áreas prioritarias de comunicaciones vía satélite y Ferrocarriles.

Tampoco constituyen monopolios, las actividades que realicen las asociaciones de trabajadores formadas para proteger sus propios intereses y las asociaciones o sociedades cooperativas de productores para que, en defensa de sus intereses o del interés general, vendan directamente en los mercados extranjeros los productos nacionales o industriales que sean la principal fuente de riqueza de la región en que se produzcan o que no sean artículos de primera necesidad, siempre que dichas asociaciones estén bajo vigilancia o amparo del Gobierno Federal o de los Estados, y previa autorización que al efecto se obtenga de las legislaturas respectivas en cada caso. Sin embargo, existe una restricción para el caso de que las mismas legislaturas, por sí o a propuesta del Ejecutivo, lleguen a derogar, cuando así lo exijan las necesidades públicas, las autorizaciones concedidas para la formación de las asociaciones de que se trata.

Finalmente, también quedan exentos de constituir monopolios, los privilegios que se concedan a autores y artistas para la producción de sus obras y los que para el uso exclusivo de sus inventos, se otorguen a los inventores y perfeccionadores de alguna mejora, lo anterior en términos de las siguientes leyes: 
También se cuenta con la Ley Federal del Derecho de Autor, ${ }^{5}$ reglamentaria del artículo 28 de la Constitución Federal, cuyas disposiciones son de orden público, de interés social y de observancia general en todo el territorio nacional, misma que tiene por objeto la salvaguarda y promoción del acervo cultural de la Nación; protección de los derechos de los autores, de los artistas intérpretes o ejecutantes, así como de los editores, de los productores y de los organismos de radiodifusión, en relación con sus obras literarias o artísticas en todas sus manifestaciones, sus interpretaciones o ejecuciones, sus ediciones, sus fonogramas o videogramas, sus emisiones, así como de los otros derechos de propiedad intelectual (Artículo $1^{\circ}$ ).

Asimismo, la Ley de la Propiedad industrial, ${ }^{6}$ cuyas disposiciones son de orden público y de observancia general en toda la República, sin perjuicio de lo establecido en los Tratados Internacionales de los que México sea parte, misma que tiene por objeto: establecer las bases para que, en las actividades industriales y comerciales del país, tenga lugar un sistema permanente de perfeccionamiento de sus procesos y productos; promover y fomentar la actividad inventiva y de aplicación industrial, las mejoras técnicas; establecer las bases para que, en las actividades industriales y comerciales del país, tenga lugar un sistema permanente de perfeccionamiento de sus procesos y productos; promover y fomentar la actividad inventiva de aplicación industrial, las mejoras técnicas y la difusión de conocimientos tecnológicos dentro de los sectores productivos; propiciar e impulsar el mejoramiento de la calidad de los bienes y servicios en la industria y en el comercio, conforme a los intereses de los consumidores.

Esta ley también contiene disposiciones para favorecer la creatividad del diseño y la presentación de productos nuevos y útiles; proteger la propiedad industrial mediante la regulación y otorgamiento

\footnotetext{
5 Publicada en el Diario Oficial de la Federación de 23 de julio de 2003.

6 Publicada en el Diario Oficial de la Federación del 27 de junio de 1991.
} 
de patentes de invención; registros de modelos de utilidad, diseños industriales, marcas, y avisos comerciales; publicación de nombres comerciales; declaración de protección de denominaciones de origen, y regulación de secretos industriales; prevenir los actos que atenten contra la propiedad industrial o que constituyan competencia desleal relacionada con la misma y establecer las sanciones y penas respecto de ellos, establecer condiciones de seguridad jurídica entre las partes en la operación de franquicias, así como garantizar un trato no discriminatorio para todos los franquiciatarios del mismo franquiciante.

\section{Ventajas}

De entre las ventajas que establece el artículo 28 de la Constitución Federal, al prohibir los monopolios y la libre concurrencia en el mercado, puedo mencionar las siguientes:

- Toda persona cuenta con el derecho humano de dedicarse a la actividad que le acomode siendo lícita, entre ellas el comercio;

- Fuera de los casos de excepción de monopolios que señalé en materia de la Ley Federal del Derecho de Autor y de la Ley de la Propiedad Industrial, se prohíbe que una persona o grupo tengan privilegios o prerrogativas para desarrollar las actividades que también precisé;

- La libre concurrencia en el mercado de bienes y servicios, alienta, promueve, motiva e intensifica la producción de bienes y servicios, lo cual trae como consecuencia su mejor calidad y la baja en sus costos, pero sobre todo en la baja de los precios en el mercado,

Lo anterior, en términos de lo que establecen los artículos $1^{\circ}, 5^{\circ}$ y 28 de nuestra Carta Magna a los que ya me referí, así como de los que para tales efectos establecen sus leyes reglamentarias, tratados internacionales de los que México sea parte y demás disposiciones 
de carácter general, que enmarca nuestro Estado de Derecho en la materia de comercio.

\section{Sanciones penales}

Las violaciones a las normas imperativas que establece el artículo 28 de la Constitución Federal, traen como consecuencia la imposición de multas y penas de prisión que establece el Título Decimocuarto del Código Penal para el Distrito Federal, bajo el rubro de "Delitos contra la Economía Pública", Capítulo I "Delitos Contra el Consumo y la Riqueza Nacionales", artículos 253 y 254, por conductas delictivas relacionadas con artículos de consumo necesario o generalizado o con las materias primas necesarias para elaborarlos, así como con las materias primas esenciales para la actividad de la industria nacional, de las que a manera ilustrativa destaco:

- El acaparamiento, ocultación o injustificada negativa para su venta, con el objeto de obtener un alza en los precios o afectar el abasto a los consumidores:

- Todo acto o procedimiento que evite o dificulte, o se proponga evitar o dificultar la libre concurrencia en la producción o en el comercio.

- La limitación de la producción o el manejo que se haga de la misma, con el propósito de mantener las mercancías en injusto precio.

- La suspensión de la producción, procesamiento, distribución, oferta o venta de mercancías o de la prestación de servicios, que efectúen los industriales, comerciantes, productores, empresarios o prestadores de servicios, con el objeto de obtener un alza en los precios o se afecte el abasto de los consumidores.

Ahora bien, independientemente de las prohibiciones y sanciones penales que establece el artículo 28 de la Constitución Federal y leyes reglamentarias a que antes me referí, por otro lado, respecto de las reglas que rigen los contratos mercantiles, destaca el Código 
de Comercio, ${ }^{7}$ mismo que regula los actos de comercio, comerciantes, y contratos mercantiles, entre otros.

Por lo que hace a los actos de comercio, sostiene Carlos Dávalos Mejía, que para algunos autores, son actos de comercio "los que se rigen por el Código de Comercio y sus leyes complementarias, aunque no sean comerciantes los que los realicen". ${ }^{8}$ Por su parte, Roberto Mantilla Molina, señala que el acto de comercio representa la clave del sistema mercantil, pues su celebración determina la aplicabilidad de esta rama del derecho. Encontramos al respecto varios criterios en la doctrina, en el sentido de que para identificar que un acto es de comercio tenemos que confirmar si cumple con alguno de los dos criterios determinantes, que son: el criterio subjetivo, en el caso de haberse realizado el acto por un comerciante, o el criterio objetivo, atendiendo al objeto del acto, como es el caso de los títulos de crédito. ${ }^{9}$

Por mi parte, considerando los mencionados criterios, estimo que para que un acto sea considerado como de comercio, y que en consecuencia le resulte aplicable toda la legislación mercantil, debe existir conexión con alguno o con ambos de los dos requisitos siguientes:

- Que sea realizado por algún comerciante.

- Que se refiera a alguna cosa mercantil.

Así tenemos que el Código de Comercio, establece en su artículo $1^{\circ}$ : "los actos comerciales sólo se regirán por lo dispuesto en este Código y las demás leyes mercantiles aplicables", mientras que el artículo $2^{\circ}$ de igual Código precisa: "A falta de disposiciones de este ordenamiento y las demás leyes mercantiles, serán aplicables

7 Publicado en el Diario Oficial de la Federación del 7 de octubre de 1889.

8 Carlos Dávalos Mejía, El Comercio Mercantil Internacional, México, Mac Graw-Hill, 2003, p. 92.

9 Roberto Mantilla Molina, Derecho Mercantil, México, Porrúa, 2003, p. 202. 
a los actos de comercio las del derecho común contenidas en el Código Civil aplicable en materia federal".

Igualmente, el artículo 75 del mismo ordenamiento señala que son actos de comercio:

I. Todas las adquisiciones, enajenaciones y alquileres verificados con propósito de especulación comercial, de mantenimientos, artículos, muebles o mercaderías, sea en estado natural, sea después de trabajados o labrados;

II. Las compras y ventas de bienes inmuebles, cuando se hagan con dicho propósito de especulación comercial;

III. Las compras y ventas de porciones, acciones y obligaciones de las sociedades mercantiles;

IV. Los contratos relativos a obligaciones del Estado u otros títulos de crédito corrientes en el comercio;

V. Las empresas de abastecimientos y suministros;

VI. Las empresas de construcciones y trabajos públicos y privados;

VII. Las empresas de fábricas y manufacturas.

VIII. Las empresas de transportes de personas o cosas, por tierra o por agua, y las empresas de turismo;

IX. Las librerías y las empresas editoriales y tipográficas;

$\mathrm{X}$. Las empresas de comisiones, de agencias, de oficinas de negocios comerciales y establecimientos de ventas en pública almoneda;

XI. Las empresas de espectáculos públicos;

XII. Las operaciones de comisión mercantil;

XIII. Las operaciones de mediación en negocios mercantiles;

XIV. Las operaciones de bancos;

XV. Todos los contratos relativos 
XVI. Los contratos de seguros de toda especie, siempre que sean hechos por empresas;

XVII. Los depósitos por causa de comercio;

XVIII. Los depósitos en los almacenes generales y todas las operaciones hechas sobre los certificados de depósito y bonos de prenda librados por los mismos;

XIX. Los cheques, letras de cambio o remesas de dinero de una plaza a obra, entre toda clase de personas;

$\mathrm{XX}$. Los valores u otros títulos a la orden o al portador, y las obligaciones de los comerciantes, a no ser que se pruebe que se derivan de una causa extraña al comercio;

XXI. Las obligaciones entre comerciantes y banqueros, si no son de naturaleza esencialmente civil;

XXII. Los contratos y obligaciones de los empleados de los comerciantes en lo que concierne al comercio del negociante que los tiene a su servicio;

XXIII. La enajenación que el propietario o el cultivador hagan de los productos de su finca o de su cultivo;

XXIV. Las operaciones contenidas en la Ley General de Títulos y Operaciones de Crédito;

XXV. Cualesquiera otros actos de naturaleza análoga a los expresados en este código.

En caso de duda, la naturaleza comercial del acto será fijada por arbitrio judicial."

Como puede observarse, la enumeración que establece el artículo 75 del Código de Comercio es meramente enunciativa, pues su fracción XXV, también considera actos de comercio a otros actos de naturaleza análoga; mientras que el artículo 76 de igual Código, excluye como excepciones los siguientes actos de comercio: 
Artículo 76. No son actos de comercio la compra de artículos o mercaderías que para su uso o consumo, o los de su familia, hagan los comerciantes, ni las reventas hechas por obreros, cuando ellas fueren consecuencia natural de la práctica de su oficio.

Por otro lado, por cuanto hace al carácter de comerciante los artículos $3^{\circ}, 4^{\circ}$ y $5^{\circ}$ del Código de Comercio que transcribo a continuación, establecen los siguientes supuestos:

Artículo $3^{\circ}$ - Se reputan en derecho comerciantes:

- Las personas que teniendo capacidad legal para ejercer el comercio, hacen de él su ocupación ordinaria;

- Las sociedades constituidas con arreglo a las leyes mercantiles;

- Las sociedades extranjeras o las agencias y sucursales de éstas, que dentro del territorio nacional ejerzan actos de comercio." Artículo $4^{\circ}$ Las personas que accidentalmente, con o sin establecimiento fijo, hagan alguna operación de comercio, aunque no sean en derecho comerciantes, quedan, sin embargo, sujetas por ella a las leyes mercantiles...

Artículo $5^{\circ}$ - Toda persona que según las leyes comunes es hábil para contratar y obligarse, y a quien las mismas leyes no prohíben expresamente la profesión del comercio, tiene capacidad legal para ejercerlo.

Finalmente, el artículo 12 del Código de Comercio establece las siguientes restricciones para ejercer el comercio:

Artículo 12. No pueden ejercer el comercio:

- Los corredores;

- Los quebrados que no hayan sido rehabilitados;

- Los que por sentencia ejecutoriada hayan sido condenados por delitos contra la propiedad, incluyendo en éstos, la falsedad, el peculado, el cohecho y la concusión. 
Cabe comentar que el sistema jurídico mexicano, establece reglas uniformes aplicables a los contratos mercantiles, ya que el Código de Comercio establece disposiciones generales y disposiciones aplicables en particular a cada uno de los siguientes contratos que regula: comisión; depósito, préstamo; compraventa; permuta; cesión de créditos; consignación y transporte terrestre.

Asimismo, es de destacarse la regulación que el Código de Comercio establece respecto del comercio electrónico, particularmente en lo referente a los mensajes de datos, la firma electrónica avanzada, los servicios de certificación de firmas; también instrumenta juicios mercantiles ordinarios, orales y ejecutivos y también regula el arbitraje comercial.

\section{ili. Derecho internacional}

Actualmente, el derecho internacional, como conjunto de normas jurídicas que regulan las relaciones entre los Estados y sus habitantes, ha cobrado relevancia como consecuencia también del fenómeno de la globalización económica y particularizando en materia de derecho mercantil, las convenciones o tratados internacionales, así como los usos y costumbres son las fuentes por excelencia del derecho Internacional, es lo que se conoce como derecho internacional convencional y derecho internacional consuetudinario, respectivamente, que desde luego nutren las relaciones comerciales internacionales; luego entonces, aquí estamos en presencia de la globalización jurídica.

\section{Derecho internacional conVEncional}

En nuestro sistema jurídico, el derecho internacional convencional resulta de suma importancia, pues los tratados internacionales se ubican como parte integrante de la Ley Suprema de toda la Unión, 
por así disponerlo el artículo 133 de la Constitución Política de los Estados Unidos Mexicanos, que señala:

Artículo. 133.-Esta Constitución, las leyes del Congreso de la Unión que emanen de ella y todos los Tratados que estén de acuerdo con la misma, celebrados y que se celebren por el Presidente de la República, con aprobación del Senado, serán la Ley Suprema de toda la Unión. Los jueces de cada Estado se arreglarán a dicha Constitución, leyes y tratados, a pesar de las disposiciones en contrario que pueda haber en las Constituciones o leyes de los Estados.

Antes de continuar, me permito hacer aquí un paréntesis, pues considero importante señalar que en este dispositivo constitucional subyace el tradicional principio de supremacía constitucional, bajo la teoría monista (nada por encima de la constitución, todo por debajo de ella), que sin embargo, a partir de cambios substanciales en la interrelación y en algunos casos de interdependencia entre los países, producto de una serie de convenciones que han celebrado, asociadas al fenómeno de la globalización, actualmente es objeto de serios cuestionamientos.

Repasando los criterios jurisprudenciales de la Suprema Corte de Justicia de la Nación, que ha vertido en torno al valor jerárquico de las leyes que emanan del Congreso de la Unión frente a los tratados internacionales, su determinación evolucionó a partir de considerar a la ley con mayor valor que el tratado internacional, luego con igual valor parta ambos y por último, mayor valor del tratado internacional sobre la ley, aperturando así una mayor incorporación del derecho convencional internacional al sistema jurídico mexicano, al tiempo que se aprecia la evolución que ha sufrido el principio de soberanía constitucional en nuestro país. ${ }^{10}$

Así es, en materia de derechos humanos, mediante labor legislativa, por decreto publicado en el Diario Oficial de la Federación de fecha

10 Cfr. Guillermo Enrique Estrada Adán, "Una visión del control de convencionalidad desde el derecho internacional", en Homenaje al maestro Edmundo Elías Musi, Porrúa-UNAM, 2014, pp. 233 - 247. 
10 de junio de 2011, la Constitución Política de los Estados Unidos Mexicanos sufrió sendas reformas y adiciones al Título Primero, denominándolo de los "Derechos Humanos y sus Garantías", antes "De las Garantías Individuales", así como a los siguientes artículos en las materias que se mencionan: 1o. Derechos humanos y discriminación, 3o. Educación, 11. Asilo político, 29. Restricción y suspensión de derechos humanos y 33. Expulsión de extranjeros, entre otros.

Con relación a lo que se viene comentando, de los artículos mencionados, se destaca el siguiente:

Artículo $1^{\circ}$.- En los Estados Unidos Mexicanos todas las personas gozarán de los derechos humanos reconocidos en esta Constitución y en los tratados internacionales de los que el Estado Mexicano sea parte, así como de las garantías para su protección, cuyo ejercicio no podrá restringirse ni suspenderse, salvo en los casos y bajo las condiciones que esta Constitución establece.

Las normas relativas a los derechos humanos se interpretarán de conformidad con esta Constitución y con los tratados internacionales de la materia favoreciendo en todo tiempo a las personas la protección más amplia.

Todas las autoridades, en el ámbito de sus competencias, tienen la obligación de promover, respetar, proteger y garantizar los derechos humanos de conformidad con los principios de universalidad, interdependencia, indivisibilidad y progresividad. En consecuencia, el Estado deberá prevenir, investigar, sancionar y reparar las violaciones a los derechos humanos, en los términos que establezca la ley $[\ldots]$

Del análisis de lo dispuesto por estos tres primeros párrafos del artículo $1^{\circ}$ de la Constitución Federal, resulta que cuando de la interpretación de las normas en materia de derechos humanos reconocidos por tratados internacionales de los que el Estado mexicano sea parte, con aplicación de los principios de indivisibilidad, interdependencia, progresividad y universalidad, se desprenda una mayor protección o beneficio para la persona, las mismas serán 
aplicables, no obstante lo dispuesto por la propia Constitución Federal, por lo que estimo que estos dogmas constitucionales no se rigen por la doctrina monista, sino por la doctrina dualista; por ello, actualmente se habla de soberanía moderna.

Retomando el tema del derecho convencional internacional, con relación a las reglas que rigen los contratos mercantiles internacionales, me permito referirme al tratado internacional más importante que México haya celebrado en materia comercial, me refiero al Tratado de Libre Comercio de América del Norte (TLCAN), que celebró con los Estados Unidos de América y Canadá, para facilitar los flujos de mercancías y capitales entre ellos, a partir del establecimiento de políticas uniformes en materia de comercio exterior que han de seguirse, como las políticas relativas a tarifas arancelarias, inversiones extranjeras, protección de la propiedad industrial, prestación de servicios financieros transfronterizos, etc. Todo el contenido del TLCAN, desde el punto de vista jurídico, puede sintetizarse diciendo que procura la uniformidad o armonización de las políticas de comercio exterior de los tres países. La idea subyacente es que el libre comercio es un medio adecuado para el desarrollo de los pueblos. ${ }^{11}$

Pero ni las políticas de comercio exterior ni el mismo tratado constituyen en realidad el libre comercio, ya que éste se formaliza con los contratos internacionales que celebran los particulares (personas o empresas) con el fin de intercambiar bienes y servicios. Las políticas de comercio exterior y los tratados de libre comercio son, por decirlo así, únicamente la escenografía adecuada para que actúen los verdaderos agentes del libre comercio que son los importadores, exportadores, fabricantes, las empresas y empresarios en suma.

Lo anterior, en virtud de que el Tratado de Libre Comercio de América del Norte fija condiciones que supuestamente han de facilitar la celebración de contratos comerciales internacionales, como

11 Jorge Adame, El Contrato de Compraventa Internacional, México, Mc Graw-Hill, 2005, p. 9. 
exportaciones o importaciones de mercancías, contratos de distribución, suministro o agencia, licencias de uso de marcas o patentes, contratos de transferencia de tecnología, contratos de transporte de mercancías, contratos de construcción o de obra terminada, contratos de prestación de servicios y otros. El éxito o el fracaso del Tratado de Libre Comercio de América del Norte finalmente se medirá en relación con la contribución que haga al desarrollo de México, Estados Unidos y Canadá, pero en forma inmediata se puede sopesar a partir del incremento o decremento de los contratos comerciales internacionales entre los tres países.

Por lo anterior, se manifiesta la necesidad de que el Tratado de Libre Comercio de América del Norte, que unifica y armoniza las políticas de comercio exterior, venga acompañado de un conjunto de principios y reglas sobre la celebración de los contratos comerciales internacionales, su ejecución e interpretación, que puedan servir como criterios para resolver los litigios o controversias que surjan con motivo de su aplicación. ${ }^{12}$

Es preciso señalar que en el orden interno, cada Estado tiene sus propias reglas aplicables a los celebrados dentro de su territorio. Pero los contratos comerciales internacionales rebasan el ámbito de competencia del derecho contractual del Estado, debido a que se trata de contratos que celebran personas de diferente nacionalidad que están asentadas en territorios de diversos Estados.

La problemática que plantea el establecimiento de reglas aplicables a los contratos comerciales internacionales se pretendió resolver con las reglas del derecho internacional privado, mediante la aplicación de uno de los derechos nacionales de las partes involucradas. La cuestión se planteaba bajo la perspectiva de definir cuál es la ley nacional aplicable al contrato. Este planteamiento, que era inherente a la idea del Estado, ya superada, como entidad soberana que se regula por su propio derecho, no tiene un resultado

12 Carlos Rodríguez González-Valadez, México Ante el Arbitraje Comercial Internacional, México, Porrúa, 2003, p. 285. 
equitativo, ya que concede una gran ventaja a la parte cuyo derecho resulta aplicable al contrato.

En efecto, una de las partes puede comprender más fácilmente los términos, alcances y condiciones del contrato y disponer de asesoría jurídica más competente y menos onerosa, mientras que la otra parte debe hacer el esfuerzo de comprender un derecho extranjero, a menudo expresado en idioma distinto al suyo. Una consecuencia práctica e inmediata de esta desventaja es que, en presencia de un problema, la parte cuyo derecho se aplica tiene más poder de negociación para hacer efectivas sus pretensiones que la otra, la cual está más dispuesta a ceder y conseguir un arreglo en vez de litigar en un derecho que apenas conoce.

La regulación de los contratos mercantiles internacionales requiere no sólo de reglas sustantivas comunes, sino también de una instancia jurisdiccional adecuada, con sus propias reglas procesales y de la capacidad de hacer efectivas las decisiones jurisdiccionales con apoyo del poder público. Se requiere entonces de un derecho sustantivo aplicable a los contratos internacionales, una jurisdicción especializada en ellos y reglas comunes para la ejecución de las decisiones jurisdiccionales.

Respecto de la solución de controversias entre las partes, Jorge Adame refiere que el TLCAN tiene algunas disposiciones. Por una parte, dispone en el Artículo 2022, párrafos 1 y 4, que los gobiernos favorezcan el arbitraje comercial y otros medios alternativos para la solución de controversias privadas y crea un Comité Consultivo de Controversias Comerciales Privadas, con la misión de que haga estudios y recomendaciones para el uso eficiente del arbitraje y otros medios de solución de controversias entre particulares en la zona de libre comercio.

Por otra parte, el artículo 2022, párrafo 3, propone que los países miembros del Tratado formen parte de la Convención de Naciones Unidas sobre el Reconocimiento y Ejecución de Sentencias Arbitrales Extranjeras (Nueva York, 1958) o de la Convención Interamericana sobre Arbitraje Comercial Internacional (Panamá, 1975), es 
decir, que tengan previsto un procedimiento ágil para la ejecución de los laudos arbitrales extranjeros. ${ }^{13}$

Con estas medidas, el Tratado de Libre Comercio de América del Norte está proveyendo de una jurisdicción especializada en materia de controversias comerciales internacionales, que es el arbitraje comercial internacional. El arbitraje comercial es realmente un órgano jurisdiccional, aun cuando ni los árbitros ni las instituciones arbitrales estén dotadas de poder público ni sean parte del poder judicial de uno de los Estados. La esencia de la jurisdicción es la decisión de las controversias; el poder sólo se requiere para la ejecución forzosa de esa decisión si el demandado no la cumple voluntariamente.

Guando los árbitros deciden una controversia mediante un laudo, realmente realizan un acto jurisdiccional, si bien pueden luego requerir el auxilio del poder judicial para la ejecución forzosa del laudo. El arbitraje comercial internacional puede llegar a ser el órgano jurisdiccional especializado para la solución de controversias comerciales privadas en la zona de libre comercio.

En la actualidad existen varias instituciones de arbitraje comercial en la zona, entre las que destacan la American Arbitration Association, el Bristish Columbia International Commercial Arbitration Center, la Comisión de Arbitraje de la Cámara Nacional de Comercio de la Ciudad de México, el Centro de Arbitraje de México y la Cámara Internacional de Comercio; además todas estas instituciones han creado una nueva organización transnacional denominada Centro de Arbitraje y Mediación Comercial para las Américas (Commercial Arbitration and Mediation Center for the Americas, CAMCA). En vista de esto, el Comité Consultivo de Controversias Comerciales Privadas concluyó en su sesión de noviembre de 1996 que no hay necesidad de promover ni de fundar nuevas instituciones de arbitraje.

Cada una de estas instituciones, y las demás que existen, tienen sus propias reglas de procedimiento arbitral y sus propias listas de

${ }^{13}$ Jorge Adame, op. cit, p. 11. 
árbitros. Las reglas de procedimiento son más o menos homogéneas y en consonancia con las Reglas de Arbitraje de la Comisión de Naciones Unidas sobre Derecho Mercantil Internacional. Las leyes de arbitraje de los tres países son también homogéneas y similares a la Ley Modelo de Arbitraje Comercial Internacional de la misma Comisión de Naciones Unidas. Los procedimientos para ejecutar los laudos que no fueren voluntariamente cumplidos están armonizados en los tres países, debido a que en todos está en vigor la Convención de Naciones Unidas sobre el Reconocimiento y Ejecución de Sentencias Arbitrales Extranjeras (Nueva York, 1958).

Finalmente, con relación a lo que he venido manifestando, no quiero omitir la protección del comercio y la inversión en nuestro país, contra el derecho extranjero que contravenga el derecho internacional, me refiero a la Ley de Protección al Comercio y la Inversión de Normas Extranjeras que Contravengan el Derecho Internacional. ${ }^{14}$

El artículo $1^{\circ}$ de esta ley prohíbe a las personas físicas o morales, públicas o privadas que se encuentren en el territorio nacional, a aquéllas cuyos actos ocurran o surtan efectos total o parcialmente en dicho territorio, así como a aquellas que se sometan a las leyes mexicanas, realizar actos que afecten el comercio o la inversión, cuando tales actos sean consecuencia de los efectos extraterritoriales de leyes extranjeras, es decir, cuando tenga o pueda tener como cualquiera de estos objetivos: que pretenda imponer un bloqueo económico o incluso limitar la inversión hacia un país para provocar el cambio en su forma de gobierno; que permita reclamar pagos a particulares con motivo de expropiaciones realizadas en el país al que se aplique el bloqueo; que prevea restringir la entrada al país que expide la ley como uno de los medios para alcanzar los anteriores objetivos. Asimismo, el artículo $2^{\circ}$ prohíbe a las personas mencionadas, proporcionar cualquier información, por cualquier

14 Publicada en el Diario Oficial de la Federación del 23 de octubre de 1996. 
medio, que les sea requerida por tribunales o autoridades extranjeros, con base en las leyes extranjeras indicadas.

También es importante lo señalado por el artículo $3^{\circ}$ de esta Ley, que obliga a las personas afectadas a informar a la Secretaría de Relaciones Exteriores y a la Secretaría de Economía, de los casos en que: pudieren verse perjudicadas en sus actividades e inversión, por los efectos de las leyes extranjeras que mencioné y reciban requerimientos o notificaciones emitidos con base en éstas. Finalmente, el artículo $9^{\circ}$ de la misma ley faculta a la Secretaría de Relaciones Exteriores, para imponer las siguientes sanciones: Por violación al primer párrafo del artículo $1^{\circ}$, multa hasta por 100, 000 días de salario mínimo general, vigente en el Distrito federal; por violación al artículo $2^{\circ}$, multa hasta por 50, 000 días de salario mínimo general, vigente en el Distrito federal; por violación al artículo $3^{\circ}$, con amonestación. Si se trata de la segunda infracción, multa hasta por 1, 000 días de salario mínimo general, vigente en el Distrito federal; en caso de reincidencia, se aplicará multa hasta por el doble del límite máximo de la sanción que corresponda.

\section{DeRECho internacional consuetudinario}

Producto de los usos y costumbres en el comercio internacional, surge el derecho internacional consuetudinario. No cabe duda que en algunas disciplinas jurídicas la costumbre se hace ley, como es el caso del derecho mercantil, sea nacional o internacional, pues la historia ha demostrado que se caracteriza y diferencia de otras ramas del derecho, porque trata de regular aquellas situaciones que de hecho, por los usos y costumbres, se dan entre los comerciantes.

Así es, en su evolución, la práctica del comercio y la solución de las controversias por parte de los mercaderes reunidos en gremios y corporaciones, fue creando un conjunto de normas de origen consuetudinario y los consulados encargados de dirimir las controversias, se convirtieron en verdaderos tribunales, que administran 
justicia sin sujetarse a formalidad alguna y dictaban sus sentencias con base en usos y costumbres generalmente aceptados, pero no transcurrió mucho tiempo sin que se recogieran por escrito las decisiones de los tribunales consulares, nacieron así, merced a esa doble practica estatutaria y jurisdiccional de las corporaciones, las primeras colecciones de normas de derecho mercantil, lo cual aconteció al crearse los estados nacionales y tratar de retomar y retener la función legislativa y jurisdiccional dejada en manos de las corporaciones y consulados de comerciantes.

Resultado de lo anterior, es práctica común y generalizada de las legislaciones de los países en la materia, la no creación de instituciones jurídicas como lo hacen respecto de otras ramas del derecho, sino que respetan, reconocen y dan validez jurídica a las prácticas de los comerciantes; en realidad, la verdadera función del legislador mercantil ha sido y es actualmente la de reconocer y no crear normas.

La anterior afirmación ha sido aceptada por la mayoría de los sistemas jurídicos alrededor del mundo y es de suma relevancia ya que la regulación mercantil mundial se sujeta al actuar de los comerciantes. Así fue desde tiempos del medioevo en los que la Lex Mercatoria cobró relevancia en la actividad comercial internacional, sin llegar a extinguirse con la positivación de las normas de carácter mercantil de los estados nacionales, y por lo contrario actualmente ya cobró nuevo auge y se le asigna como la nueva Lex Mercatoria.

Esta particularidad aparece como uno de los factores por el que no existe uniformidad en las reglas que regulan los contratos mercantiles internacionales; aunado a que los usos y las costumbres varían de comunidad en comunidad y más propiamente de legislación en legislación y de sistema jurídico a sistema jurídico o inclusive con mayores diferencias entre las familias jurídicas, por ejemplo el sistema del common law estadounidense, en donde no se distingue entre un contrato civil y un contrato mercantil y el sistema jurídico mexicano en que si se encuentran diferenciados estos contratos. 
No obstante lo anterior, debe considerarse que existen determinados conceptos, normas e instituciones de carácter mercantil, que son denominador común, porque son aplicadas en el ámbito internacional, son aceptadas y reconocidas por los países y tal es el caso del uso generalizado del principio de la autonomía de la voluntad de las partes, para elegir el derecho aplicable, para adherirse total o restrictivamente a los instrumentos internacionales que regulan los contratos mercantiles, elección de los tribunales para dirimir las controversias y otros.

Pero también debe destacarse que, cuando dichas normas se tratan de codificar, varían en su esencia de un país a otro, de un bloque económico a otro, en donde persiste la tendencia a proteger intereses de los países sobre todo más desarrollados, este es el verdadero problema que hoy ocupa mi atención e interés, la ausencia de normas uniformes que regulen los contratos mercantiles internacionales.

Para el establecimiento de las obligaciones en esos instrumentos jurídicos, la interpretación de sus cláusulas y en general para la solución de las controversias que surjan por su incumplimiento, apoyadas en el principio mundialmente reconocido de la autonomía de la voluntad, las partes pactan una serie de normas o reglas bajo tres vertientes: una o varias legislaciones nacionales; tratados y convenciones Internacionales y; usos y costumbres conocidos como Nueva Lex Mercatoria, la que en muchos casos tiene aplicación preferente sobre el derecho nacional.

Adicionalmente debe indicarse que ha cobrado gran auge el uso de medios electrónicos, para la celebración de contratos mercantiles internacionales; estas nuevas formas de contratación, obligan a buscar la adecuación de la legislación nacional, al tiempo que se reclama su unificación general, como tema de discusión actual en foros nacionales, regionales y mundiales. El problema de esa falta de uniformidad puede verse desde los ángulos de la interpretación y cumplimiento de las reglas o normas que rigen los contratos mercantiles internacionales (conflicto de leyes en el tiempo y en el 
espacio) y de la solución de las controversias que surjan entre las partes con motivo del incumplimiento de las obligaciones a su cargo (conflictos de jurisdicciones).

Como fuente primordial del derecho mercantil, los usos y las costumbres en el comercio, la Lex Mercatoria, que de hecho rige los contratos mercantiles internacionales; es un conjunto de principios generales y reglas costumbristas, referidas espontáneamente y creadas dentro de la estructura del comercio internacional, sin referencia a un sistema jurídico nacional en particular. ${ }^{15}$ Los principios generales de la Lex Mercatoria consisten en:

- Las prestaciones contractuales deben ser equilibradas;

- La interpretación de buena fe de los convenios;

- La presunción de competencia internacional;

- La obligación para el acreedor de una obligación inejecutada de minimizar el perjuicio;

- La presunción, a falta de acción, de renuncia a las sanciones contractuales;

- El deber de cooperación de las partes;

- La exigencia de una diligencia normal, útil y razonable de las partes en el cuidado de sus intereses;

- La validez de la aceptación tácita del contrato;

Las reglas de interpretación de los contratos, tales como la auto determinación y la autorresponsabilidad, la autonomía y libertad contractual, la buena fe, la verdadera intención de las partes, normas del efecto útil, transparencia sustantiva en un grupo de sociedades y ampliación del efecto relativo de los contratos, la igualdad y equidad contractual, la confianza y seguridad.

15 Apud Miguel Acosta Romero, Nuevo derecho mercantil, México, Porrúa, 2000, p. 73 . 
Ahora bien, en la práctica del comercio internacional se ha puesto en evidencia que en lugar de la legislación nacional, las partes prefieren sujetar los contratos mercantiles a las normas de tratados y convenciones internacionales y principalmente a las normas consuetudinarias de la nueva Lex Mercatoria, que son mundialmente aceptadas, es un derecho supranacional que ya dejó atrás a las legislaciones nacionales y tan es así que ha introducido contratos tipo, en materia de transporte aéreo de pasajeros, contrato de licencia de programas de informática, contrato de fletamento, de factoring, de joint venture o de know how internacionales, o los incoterms (Internacional Comercial Terms) que son siglas que contienen normas que vinculan a las partes, con base en las cuales se resuelven vía el arbitraje las controversias que surgen entre las partes, constituyendo verdadera jurisprudencia las resoluciones de los árbitros internacionales, sin embargo no se cuenta con principios generales para la uniformidad de las reglas que regulan los contratos mercantiles internacionales.

En el ámbito internacional se han presentado dos iniciativas por tratar de llevar un registro de principios aplicables. La primera se circunscribe a los países adheridos a la Comunidad Europea y presupone la elaboración de una clase de compendio (Restatement) europeo del derecho de los contratos, una recopilación de principios y reglas generales en materia de contratos y la segunda la constituye el proyecto de UNIDROIT (Instituto Internacional para la Unificación del Derecho Privado) de elaboración de principios para los contratos comerciales internacionales. ${ }^{16}$

También se destaca la importante labor de otros organismos internacionales, que han elaborado una serie de normas tendientes a la unificación de los contratos mercantiles, para ser aplicadas por los países participantes y por los que se adhieran a las mismas, ello a través de diversos instrumentos como la Convención sobre la Ley aplicable a las Obligaciones Contractuales celebrada en Roma el 19 de junio de 1980; la Convención sobre los Contratos de Com-

16 Miguel Acosta Romero, op. cit., p. 77. 
praventa Internacional de Mercaderías de UNCITRAL de 1988; los Principios del Instituto Internacional para la Unificación del Derecho Privado UNIDROIT sobre los Contratos Mercantiles Internacionales de 2010, la Convención Interamericana sobre Derecho Aplicable a los Contratos Internacionales de 1994, entre otros.

Pero a pesar de que con la adopción de los instrumentos antes mencionados se ha propuesto a las partes la aplicación de normas uniformes a los contratos mercantiles internacionales, por otro lado, deja el camino abierto para que sus relaciones contractuales puedan estar sujetas a diversas legislaciones, usos y costumbres, ya que la autonomía de la voluntad como principio mundialmente aceptado, permite a las partes la libre elección del derecho que se aplicará y de no acordarlo, establece reglas entre las que prevalecen la relativa a la aplicación del derecho del Estado con el que se tengan los vínculos más estrechos (ubicación de las mercancías, domicilio de los contratantes) o bien la aplicación de usos y costumbres (nueva Lex Mercatoria), como ocurre con los instrumentos que ya cité, independientemente de la unificación necesaria a la legislación que rige los contratos mercantiles internacionales.

A partir de la interrelación y en muchos casos interdependencia económica de los países en esta sociedad globalizada, la regulación de las relaciones comerciales en el seno de las legislaciones internas de los estados, ha sido rebasada por acuerdos, convenciones y tratados internacionales que en muchos caso obedecen más a intereses de grupos de naciones o de hombres poderosos política y económicamente, que se asocian formando bloques económicos, que a los intereses de los países que se encuentran en el subdesarrollo y que se insiste, como el nuestro luchan por encontrar igualdad en las relaciones comerciales.

Esta realidad se nos muestra agresiva y capaz de superar toda expectativa y cualquier capacidad de pronóstico y reacción de quienes están encargados de diseñar y construir las instituciones jurídicas, de quienes nos ocupamos de estudiarlas y hacer de ellas nuestra he- 
rramienta de trabajo cotidiano, así como de aquellos quienes tienen encomendada la importante tarea de impartir justicia.

La técnica legislativa y la jurisprudencia coexisten y asisten juntas con cierto asombro al espectáculo que brinda la dinámica del mercado en el plano internacional, que asedia de manera inexorable el quietismo de instituciones jurídicas nacionales y extranjeras, a las que no queda más que adaptarse a una velocidad vertiginosa no siempre posible, o perecer y ser sustituidas por conductas comerciales que por carencia de regulación apropiada, pueden afectar no sólo la seguridad jurídica, sino la viabilidad económica de las transacciones mercantiles.

El progreso científico y tecnológico y los cambios políticos son fenómenos a los que desde los nuevos enfoques filosófico-políticos respecto de los derechos humanos y sus garantías, hasta las nuevas herramientas a través de las cuales es posible la perpetración de hechos delictivos, ninguna rama del derecho es ajena, ya que renuevan la práctica del derecho constitucional, y por ello es que difícilmente existe una subdisciplina jurídica que no acuse el impacto de los vertiginosos cambios característicos de nuestro tiempo. El derecho mercantil no puede ser la excepción. En la actualidad, y tras siglos de haber sido una disciplina jurídica vanguardista por excelencia, impulsada por una dinámica propia, el derecho mercantil se enfrenta a un escenario inédito en donde muchas de sus instituciones y figuras aparecen hoy rezagadas.

Este entorno, más allá de constituir un motivo de legítima preocupación en el aspecto práctico, representa también la oportunidad para los juristas de llevar adelante un ejercicio de reflexión y creatividad que impulse la actualización de una disciplina que por su naturaleza misma, no puede darse el lujo de atestiguar con pasividad la enorme presión transformadora que las dinámicas de la economía globalizada de mercado imponen a nuestra rama.

Existen disciplinas que sólo se explican en función del papel que a posteriori del acontecer socioeconómico les toca desempeñar. Este 
yerro convertido en privilegio no es uno que le corresponda al derecho mercantil. Desde sus orígenes, nuestra rama ha servido como motor para la evolución y el desarrollo del comercio para la actividad económica y llevar a cabo las grandes transformaciones del derecho privado. En tal virtud, se encuentra asociado a la dinámica con que la capacidad humana se proyecta para construir instituciones, estructuras sociales y económicas más eficaces y eficientes, aprovechando tanto la experiencia histórica como las virtudes creativas, que son puestas en práctica para resolver nuevas necesidades e inquietudes socioeconómicas. Si acaso fuera demasiado pretencioso sostener que nuestra disciplina impulsa la historia del derecho, cuando menos es necesario reconocer que va de la mano con ella.

Este equilibrio, tras algunas centurias de haberse mantenido como una realidad inexorable en el ámbito jurídico, hoy parece romperse o ceder ante el empuje incontenible de una actividad económica globalizada que parece desenvolverse con una lógica propia. La expansión de los mercados internacionales, primero en mercancías, luego en servicios y después en flujos financieros, es el proceso que ha marcado en buena medida la historia del siglo que acaba de finalizar y que representa, sin duda, el mayor desafío al que los juristas podemos enfrentarnos en la centuria que recién comienza.

El movimiento de la economía y el comercio internacionales, a más de numerosas implicaciones políticas que constituyen por sí mismas una ocasión para una reflexión aparte, involucra como uno de sus rasgos más característicos y sobresalientes la difícil tensión entre la vigorosa pujanza con que se desenvuelven los mercados mundiales y sus protagonistas, por un lado, y la necesidad de establecer regulaciones jurídicas estables y uniformes para orientar un universo cada día más heterogéneo de operaciones y transacciones, por el otro.

Una muestra clara de esta situación es la contratación comercial a través del uso de medios electrónicos, situación que, sobre todo a partir de las dos últimas décadas, ha alterado las reglas legales y las 
añejas prácticas comerciales de contratación, ya que se suprimió el documento escrito, la presencia de las partes ahora es virtual, pueden firmar electrónicamente, entre otras formas, ayudados del uso de las tecnologías de la información y comunicación, destacándose la contratación a través de internet, han rebasado cualquier expectativa de expansión comercial nacional y extranjera.

Tal panorama refleja por un lado, como se anula un importante espacio para la acción de los estados con miras a orientar su vida económica en beneficio de sus intereses nacionales, por el otro, parecería insinuarse una suerte de anomia que para muchos sería motivo de genuina preocupación. Sin embargo ese motivo de inquietud es en buena parte artificial. En efecto, más que tratarse de una anomia en el ámbito del tráfico mercantil, estamos ante un silencio, ese sí preocupante, por parte de los especialistas y estudiosos del Derecho que no han sabido o no han querido acceder al llamado que reclama una nueva sistematización de ese extenso universo de instituciones y figuras contractuales que intervienen en esta nueva dinámica económica mundial.

La falta de ese instrumental teórico tiene importantes consecuencias, muchas de las cuales repercuten en la propia estructura histórica del derecho mercantil que, como referíamos antes, se ha caracterizado a lo largo de su evolución por marchar de la mano, cuando no ser impulsor directo, de los grandes cambios en la historia del derecho privado. La técnica jurídica ha sido, desde sus orígenes en el mundo romano, una interminable y fecunda labor de sistematización; lo que la ha caracterizado en el ámbito específico del derecho mercantil ha sido la proyección dinámica y progresiva que en otras épocas se supo imprimir a esa tarea. Hoy es preciso reivindicar esa nota distintiva de nuestra disciplina asumiendo un compromiso intelectual serio ante un desafío monumental, pero no insuperable.

El tráfico mercantil se expande en nuestros días haciendo uso de un sinfín de herramientas jurídicas de la más variada índole, separando las etapas en una multitud de transacciones diversas que regulan 
distintos aspectos de cada operación. La creciente especialización de la materia manifiesta, en consecuencia, una diversificación de sus contenidos. Esta variedad y heterogeneidad de figuras contractuales nos miran desafiantes, más no por ello debe ser motivo de perplejidad para el jurista, sino todo lo contrario, ocasión para hacer uso del instrumental teórico básico con objeto de imprimirle una forma, una estructura orgánica a esa variedad de actos jurídicos que suelen aparecer como una diversidad informe y confusa.

Si bien las doctrinas difieren sobre sus contenidos y alcances, si bien hoy parece existir una relativa distancia entre el derecho mercantil tradicional y el derecho de las transacciones comerciales internacionales, es indiscutible que existen principios rectores y pautas de sistematización capaces de proporcionar una óptica integradora para este cúmulo de procesos jurídicos que caracterizan el momento actual. Es en esta perspectiva que debemos colocarnos para ensayar un intento de renovación estructural a fondo de nuestra disciplina y comprender la renovada dinámica que hoy la caracteriza, así como señalar sus proyecciones y estar así en condiciones de anticipar futuras evoluciones.

No puede abrigarse duda alguna de que el derecho es un instrumento social que ante todo debe servir al progreso de la sociedad. Hoy en día, cabría sostener que es de las pocas herramientas con las que países en situación de rezago económico como el nuestro, con un déficit social ofensivo, puede enfrentar los retos de una economía globalizada preservando para sí espacios básicos de decisión que permitan cumplir con las funciones básicas del Estado en beneficio de nuestra población. El contexto, sin embargo, presenta una dificultad, que se vincula con el rol protagónico que muchos organismos multilaterales han asumido en décadas recientes, y que muchas veces deciden sobre la base de una errónea interpretación de las dinámicas económicas particulares de cada nación, cuando no con base en una absoluta falta de información al respecto. 
Como expresión de soberanía, el derecho debe recuperar para sí esa capacidad de influir sobre la marcha del acontecer social y orientar los procesos que permitan al país salir victorioso de la interminable lucha contra la pobreza y el atraso económico y social. El fenómeno mundial de la globalización, impone a los países el establecimiento de instrumentos jurídicos que posibiliten y faciliten un mejor aprovechamiento y desenvolvimiento de las relaciones comerciales entre personas de diferentes países y entre estados, entre los que se destacan los contratos mercantiles internacionales celebrados ya tradicional o ya electrónicamente, sin embargo, la falta de uniformidad en las reglas generadoras de las obligaciones y de estos instrumentos jurídicos, se traduce en el empleo innecesario de tiempo y pérdida de recursos económicos de las partes contratantes, así como en el deterioro de sus relaciones comerciales.

Consciente de este espacio limitado para ahondar más, aspiro a motivar la investigación de juristas y estudiosos del derecho sobre la problemática aquí expuesta, de la falta de uniformidad en las reglas que rigen los contratos mercantiles internacionales, pero sobre todo que la labor legislativa nacional e internacional se preocupen y ocupen en la creación de normas tendientes a resolver tal problemática. 